\title{
ResearchArticle
}

\section{Incidence of seed mycoflora in different cultivars of safflower}

\author{
D. Amrutha Gayathri and V. Krishna Rao
}

\begin{abstract}
SUMMARY
An investigation was conducted to detect the associated seed mycoflora in safflower and its control. A total of 19 safflower seed samples were collected from major growing areas of safflower. Blotter method and agar plate methods were used for detection of seed mycoflora of safflower seeds. Across the two methods adopted, a total of seven fungal genera including Alternaria, Aspergillus, Chaetomium, Rhizopus, Curvularia and Fusarium were detected. The fungi detected were identified based on their cultural and morphological characteristics. The fungal species namely Alternaria carthami, Aspergillus niger were found associated with all the tested hybrids/varieties/germplasms while species of Chaetomium sp., Rhizopus sp., Curvularia sp. and Fusarium sp. were not detected in some of the hybrids/varieties/ germplasms. Among the seven fungal species detected the occurrence of Alternaria carthami was high 47.94 per cent followed by Aspergillus niger. The cultivar, Nira showed higher per cent incidence of seed mycoflora. Per cent incidence of seed mycoflora varied across the methods adopted and cultivars tested the highest per cent incidence of $46 \%$ was observed with the fungus Alternaria carthami on Nari NH1 in blotter method. Out of the two methods tested blotter method was found superior over agar plate method in which higher number of fungi were recorded.
\end{abstract}

Key Words : Safflower, Mycoflora, Alternaria carthami, Seed borne

How to cite this article : Gayathri, D. Amrutha and Rao, V. Krishna (2018). Incidence of seed mycoflora in different cultivars of safflower. Internat. J. Plant Sci., 13 (1): 114-117, DOI: 10.15740/HAS/IJPS/13.1/114-117.

Article chronicle : Received : 29.07.2017; Revised : 25.11.2017; Accepted : 10.12.2017 